\title{
PROYECTO URBANO INTERVENCIÓN INTEGRAL BARRIO GRAN TOBA
}

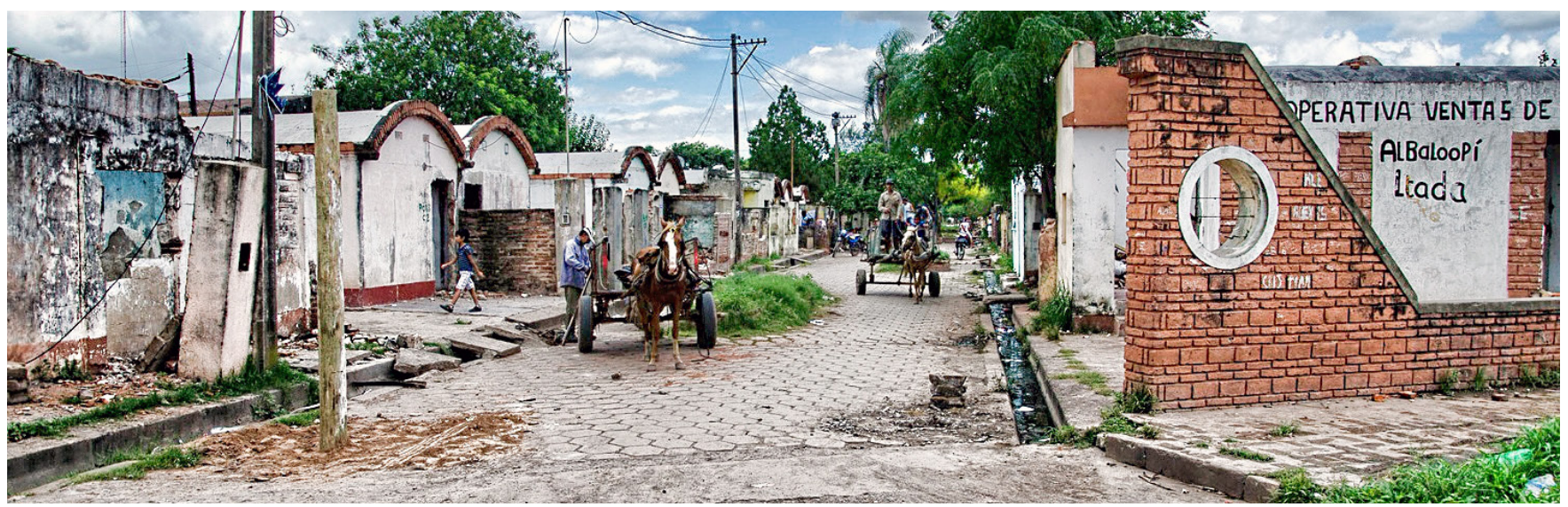




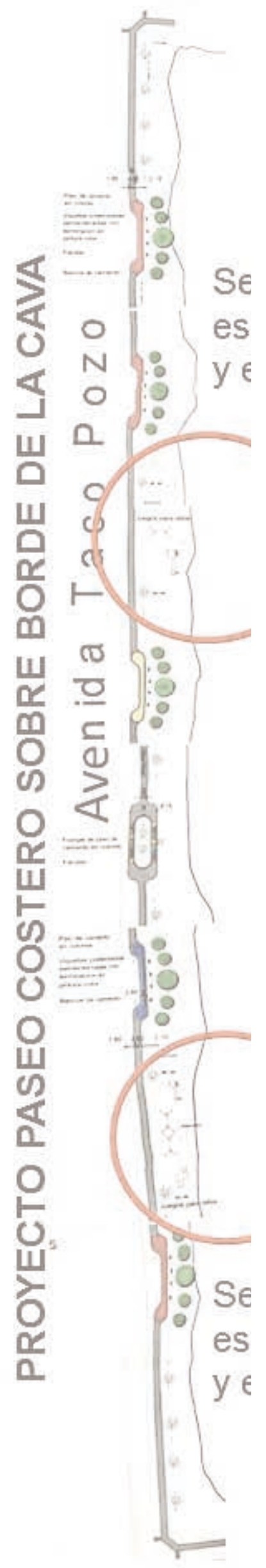

\section{RESUMEN}

El siguiente artículo pretende divulgar los avances que se están llevando a cabo en el Proyecto de Intervención Integral del Área Gran Toba, en la ciudad de Resistencia, provincia del Chaco, República Argentina. La complejidad — social y urbana — de los barrios que componen el sector ha determinado la necesidad de una acción conjunta de diferentes jurisdicciones del Estado, en todas sus escalas, bajo la coordinación general del Instituto Provincial de Desarrollo Urbano y Vivienda (IPDUV). La importancia de esta intervención tiene un doble carácter. Por un lado, configura una reparación histórica a las comunidades originarias que viven en el sector desde hace más de cuatro décadas. Por otro lado, representa el rol activo del Estado en el desarrollo de la ciudad y en la mejora integral del hábitat.

\section{ABSTRACT}

The following article aims to divulge the advances that are taking place in the project Intervención Integral del Área Gran Toba, en la ciudad de Resistencia, provincia del Chaco, República Argentina. The complexity - social and urban - of the neighborhoods that compose the sector has determined the need of a joint action of different jurisdictions of the State, in all his scales, under the general coordination of the Instituto Provincial de Desarrollo Urbano y Vivienda (IPDUV). The importance of this intervention has a double character. On the one hand, it sets a historical repair to the original communities that live in the sector for more than four decades. On the other hand, it represents the active role of the State in the development of the city and in the integral improvement of the habitat.

\section{EBEL, GABRIELA A.}

Arquitecta, egresada de la Universidad Nacional del Nordeste. Maestranda en Planificación Urbana y Regional. Becaria de Perfeccionamiento (SGCyT-UNNE). Auxiliar docente de la Cátedra Desarrollo Urbano I (FAU-UNNE).

\section{FERNÁNDEZ, MARÍA LAURA}

Arquitecta, egresada de la Universidad Nacional del Nordeste. Maestranda en Planificación Urbana y Regional. Becaria de Perfeccionamiento (SGCYT - UNNE). Auxiliar docente de la Cátedra TFC-Taller C (FAU-UNNE)

Gerencia de Proyecto y Programación del Instituto de Provincial de Desarrollo Urbano y Vivienda. 
"El proyecto de Intervención Integral del Área Gran Toba consiste en el abordaje complejo de un sector desatendido y degradado de la ciudad de Resistencia"

\section{DATOS DEL ÁREA DE INTERVENCIÓN}

Ubicación: cuadrante nordeste de la ciudad de Resistencia, limitada por la ruta N. ${ }^{\circ}$ 11, la Av. 25 de Mayo y las lagunas Toba y Luisa - Ghío, provincia del Chaco, República Argentina $\left[27^{\circ} 25^{\prime} 49.72^{\prime \prime S}\right.$ - 59 0'22.80"O].

Características físicas del área: se trata de una zona que presenta una mixtura de usos residenciales y de servicios de ruta. El asentamiento original del barrio Toba, sobre las vías del tren, rompe el esquema ortogonal de la cuadrícula de la ciudad. Los barrios aledaños ocuparon espontáneamente las zonas vacantes y los bordes de lagunas, que previamente a la intervención carecían de atractivo paisajístico y poseían limitadas funciones como reservorios naturales, por la falta de mantenimiento y el vertido de elementos de desecho.

Características sociales del área: viven en el sector de intervención unas 3000 personas. Aún residen allí algunos de los pobladores originales del barrio Toba, de la etnia qom. Muchos de los habitantes actuales son descendientes de aquellos pobladores originales: hijos, nietos y biznietos, quienes ante la necesidad habitacional cohabitan en "familias extendidas" dentro de las viviendas originales, o mediante autoconstrucción -en muchos casos con materiales de descartehan construido precarias viviendas, asentándose en terrenos vacantes, aledaños al barrio original.

\section{MEMORIA DESCRIPTIVA}

El proyecto de Intervención Integral del Área Gran Toba consiste en el abordaje complejo de un sector desatendido y degradado de la ciudad de Resistencia, donde coexisten diversos conflictos que definen un importante grado de segregación socio-territorial.
El área de intervención se encuentra localizada en el cuadrante nordeste de la ciudad, limitada por la ruta N. ${ }^{\circ}$ 11, la Av. 25 de Mayo y las lagunas Toba y LuisaGhío. Incluye a los barrios Toba, Chelliyí, Crescencio López, Cotap y algunos asentamientos informales existentes en el entorno. Resulta un área problemática de la ciudad, con un importante nivel de degradación del hábitat y la consecuente disminución de calidad de vida de sus habitantes, producto de la alta densidad poblacional, el hacinamiento originado en las viviendas y la existencia de tres sectores de asentamientos informales, de viviendas precarias originadas en lotes baldíos, terrenos con destino público y bordes de lagunas.

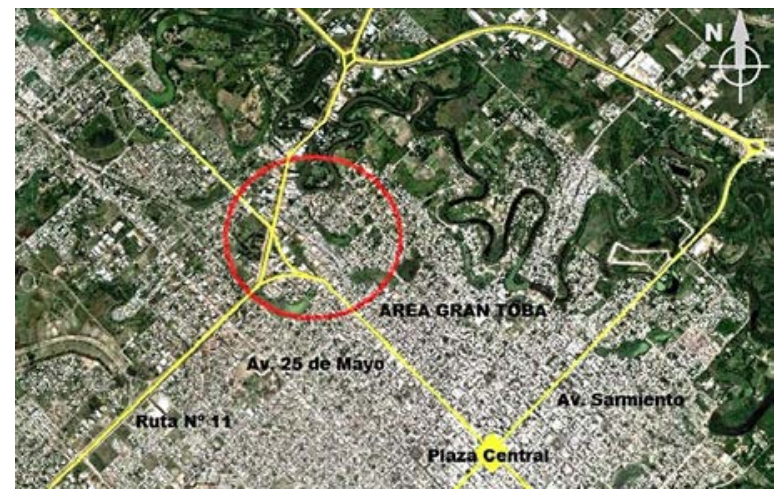

Imagen 1. Área Gran Toba dentro de la ciudad de resistencia. Fuente: equipo técnico IPDUV

La traza original del barrio responde a un asentamiento espontáneo sobre las vías del tren que data de más de cuarenta años y se produjo como consecuencia de los procesos migratorios provenientes del interior de la provincia que provocaron el desplazamiento forzoso de varios grupos de pueblos originarios en esa época. En la década del 70 se construyeron 220 viviendas que mejoraron la calidad de vida de las familias allí asentadas. En los siguientes años los hijos de estos primeros pobladores fueron ocupando los terrenos aledaños. A partir del año 2000 se intervino el sector 


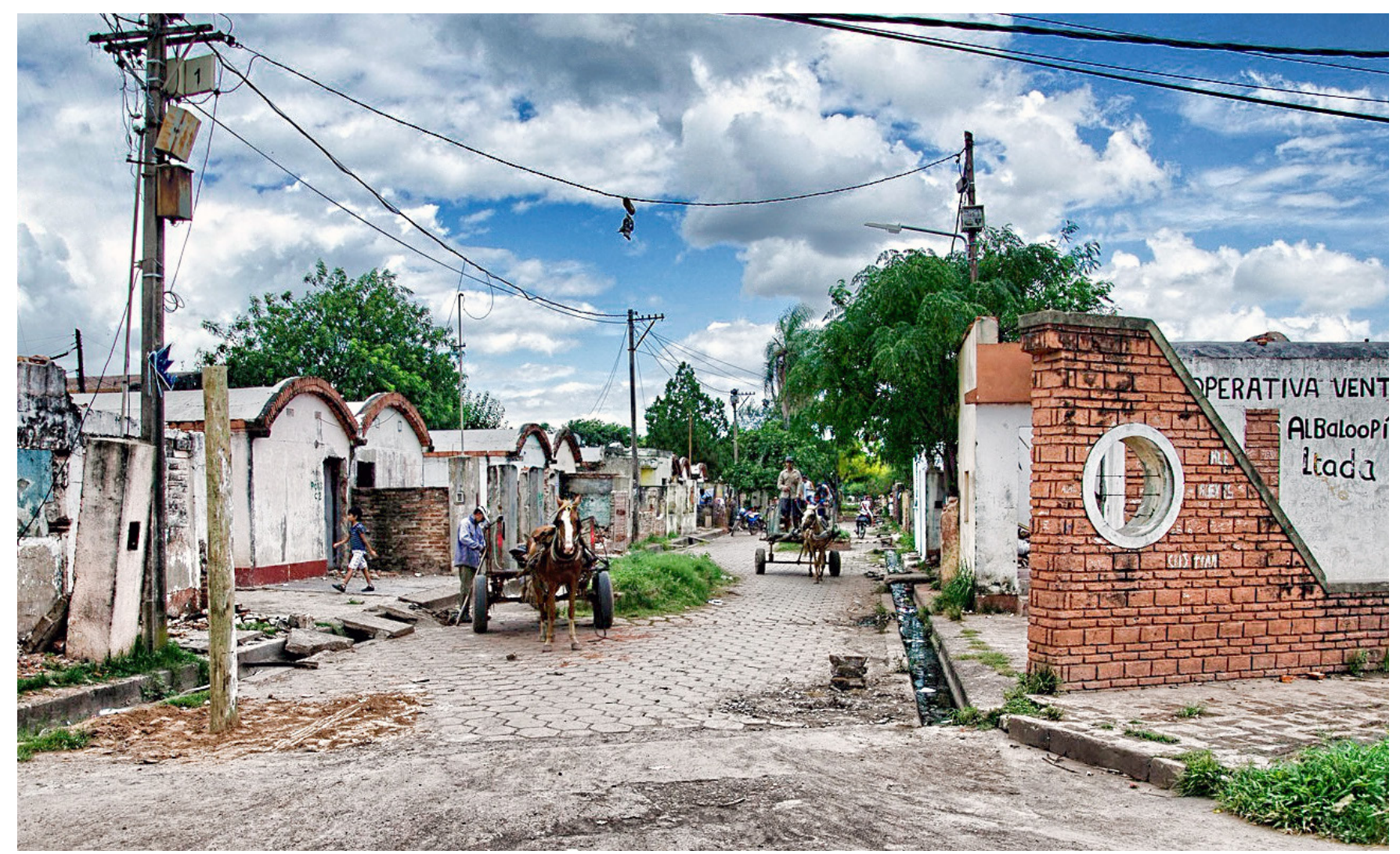

Imagen 2. Situación original en el acceso del barrio Toba. Fuente: equipo técnico IPDUV

con diferentes programas de viviendas y mejoramientos que lograron disminuir las necesidades de viviendas, pero no lograron dar una respuesta integral a las problemáticas del hábitat.

Actualmente viven en el sector de intervención unas 3000 personas, según fuentes del área de Salud, pero se cree que el número asciende a 5000 en algunas épocas del año. Los habitantes de las viviendas conforman "familias extendidas", en las cuales varias generaciones conviven en una misma casa. Una gran parte de estas familias vive en asentamientos irregulares que fueron creciendo en todas las zonas libres y bordes de lagunas cercanas, con graves problemas de hacinamiento, en terrenos inundables y en condiciones de insalubridad, considerando los focos de contaminación existentes por la falta de evacuación de efluentes cloacales, los escurrimientos pluviales anegados, los materiales de construcción utilizados y el estado de conservación de las viviendas en general.

Las problemáticas sociales acuciantes del barrio y los asentamientos aledaños se vieron acrecentadas por un marcado aislamiento del sector en la ciudad, a raíz de diversas cuestiones urbanas, que se detallan a continuación.

\section{Accesibilidad}

El acceso desde ruta nacional $N{ }^{\circ} 11$ nunca fue resuelto, y se convirtió en un foco de accidentes viales y de peligro constante para los vecinos. Asimismo, el segundo acceso al barrio, por Av. 25 de Mayo, no fue materializado. Además, su desarrollo lineal —-sobre una calle muy angosta, casi de escala peatonal, producto del diseño original del barrio - lo aísla de la ciudad y dificulta el acceso de servicios básicos: transporte público, ambulancias, bomberos, policías, etc.

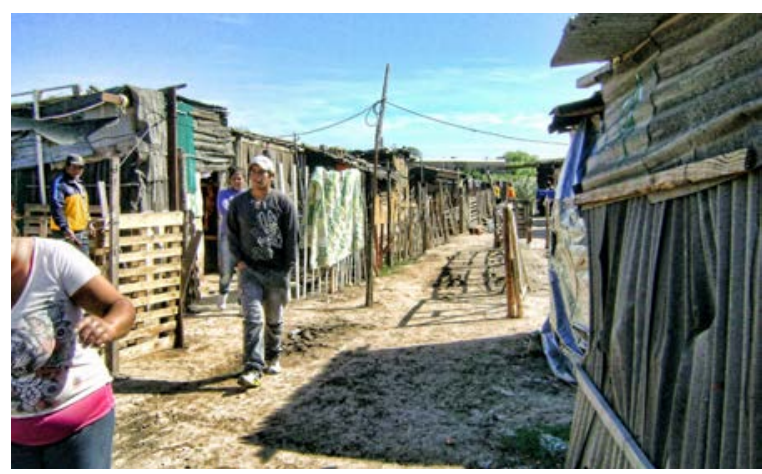

Imagen 3. Situación original en el interior de uno de los asentamientos informales aledaños al barrio Toba. Fuente: equipo técnico IPDUV

\section{Espacios verdes}

El barrio carecía totalmente de espacios verdes destinados al uso público. El único sector destinado a Reserva Municipal se encontraba en condiciones de total abandono. El barrio está delimitado por lagunas, que lejos de ser un espacio concebido como reserva natural, ha sido invadido por las viviendas que fueron asentándose en sus bordes. Los residuos se acumulan entre la vegetación y conforman un entorno de contaminación y degradación.

\section{Seguridad}

Existen conflictos entre diferentes grupos de la misma etnia. La venta de droga ha encontrado en el barrio 


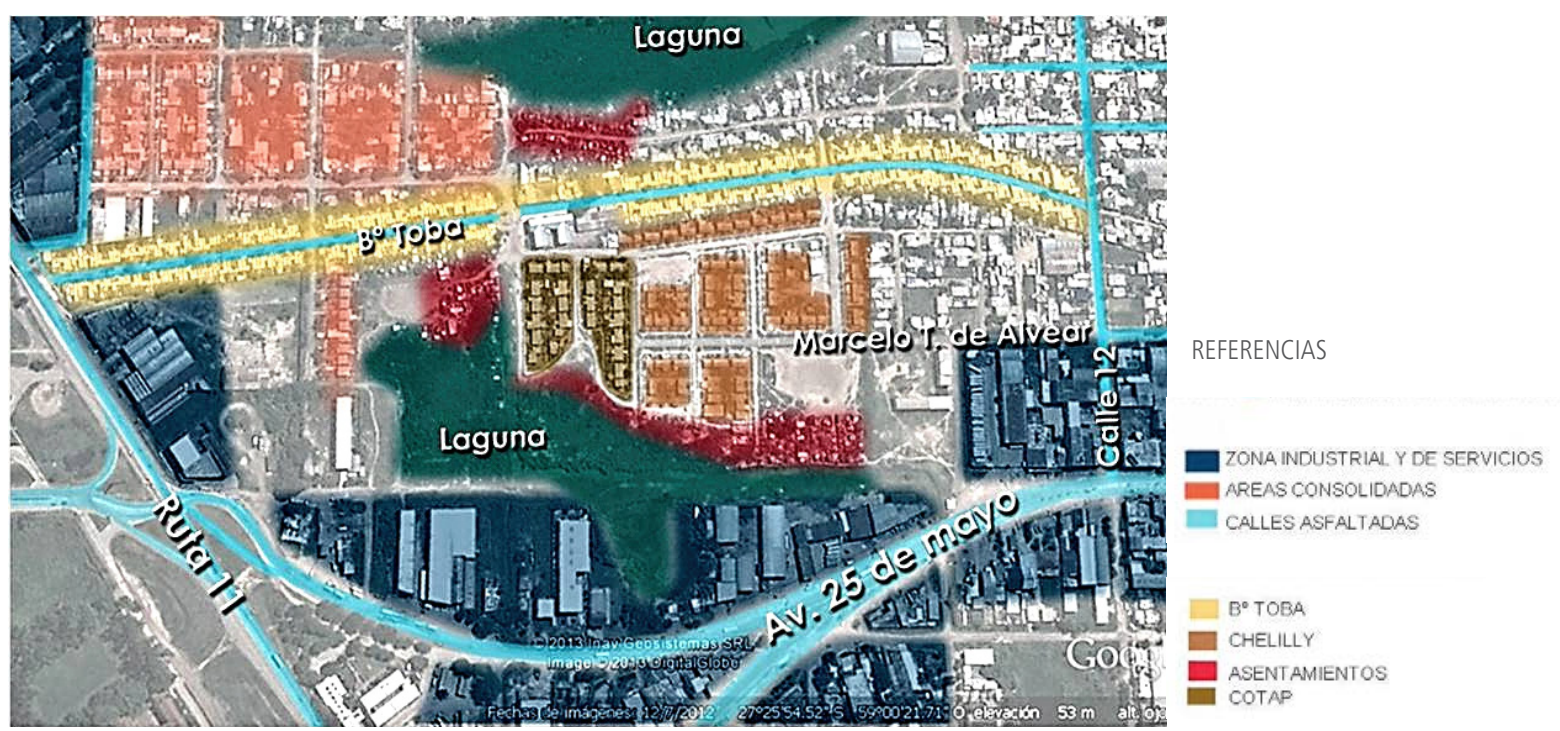

Imagen 4: Área Gran Toba. Barrio Toba y asentamientos aledaños. Fuente: equipo técnico IPDUV

un espacio propicio. La sumatoria de problemas sociales de larga data ha derivado - entre otras cosas - en un aumento del consumo de drogas por parte de los jóvenes, que se multiplica día a día. El alto grado de delincuencia provoca persecuciones policiales permanentes en las intercalles del barrio.

\section{Equipamientos sociales}

Previamente a la intervención, el barrio contaba con las siguientes instituciones:

1. Una escuela primaria: con capacidad para cuatrocientos alumnos. Asistían solo doscientos, debido a su mal funcionamiento, por conflictos internos.

2. Una escuela secundaria: funciona en un sector de la iglesia católica, que fue cedida a la comunidad. Se improvisaron cuatro aulas, donde se dictan clases a cinco cursos.

3. Centro de nivel inicial: funciona en un edificio construido para este fin, pero actualmente está desbordado por la elevada concurrencia.

4. Centro de salud: con edificio propio a punto de inaugurarse.

5. Cocina-comedor social: pertenece a la Cruz Roja y funciona en una vivienda que fue adaptada para este fin.

6. Registro Civil: funciona en una vivienda adaptada, aunque totalmente obsoleta. Presta servicio a un área muy amplia de la ciudad y está ubicado en una zona muy poco accesible.

7. Deportivo: una cancha de fútbol, que funciona en un sector destinado a equipamiento. Es un lugar de encuentro y esparcimiento del barrio y se utiliza a diario.

8. Religioso: existen actualmente ocho iglesias evangélicas (dos de ellas oficiales), distribuidas en el interior del barrio.

9. Local de venta de artesanías: funciona en el acceso a ruta nacional N. ${ }^{\circ} 11$. Su localización presenta dificultades de acceso para los posibles compradores, por tratarse de una vía rápida de excesivo tránsito.

\section{EL BARRIO Y LOS ASENTAMIENTOS ALEDAÑOS}

- Barrio Toba: conforma el asentamiento original, donde se construyeron 220 viviendas mediante la acción estatal. Habitan allí 372 familias.

- Crescencio López: fue el primer asentamiento en surgir. Está constituido por sesenta familias, grupos que oscilan entre dos y seis integrantes. La actividad económica que predomina son las informales de subsistencia, tanto como los planes sociales, pensiones y cooperativas.

Los módulos habitacionales están, en general, construidos con materiales precarios: chapa-cartón, cobertor negro, maderas, etc.; los pocos de materiales resistentes se encontraban en malas condiciones de construcción, generando situaciones de peligro para sus habitantes. A esto se suman condiciones insalubres de vida que provocan constantes enfermedades en los menores.

- Chelliyí: constituido por 84 familias, se ubican en una manzana municipal destinada a equipamientos.

- Cotap: constituido por 81 familias y ocupan un terreno privado al borde de la laguna Toba.

Tras un minucioso análisis, el equipo técnico del Instituto Provincial de Desarrollo Urbano y Vivienda del Chaco ha definido en el siguiente diagnóstico-resumen los aspectos más relevantes del Área Gran Toba, como sustento para la intervención integral:

1. deterioro físico-ambiental del área;

2. alto grado de hacinamiento a escala intralote;

3. alta densidad demográfica a escala barrial;

4. sector desvinculado de la trama vial de la ciudad;

5. la dotación de equipamiento es insuficiente para atender las necesidades básicas de la población; 
6. vulnerabilidad social de la población;

7. alto deterioro de las viviendas de materiales "aptos" existentes en el área y

8. asentamientos muy precarios en condiciones físicoambientales de alto riesgo para sus habitantes.

\section{PROPUESTA DE INTERVENCIÓN INTEGRAL}

Mediante el proyecto de intervención integral se pretende dar una respuesta sistémica, que no solo como un proyecto participativo e interdisciplinario, que mediante consenso entre los diferentes actores involucrados logre respetar las pautas culturales y la identidad del conjunto de habitantes del sector, considerando especialmente las características culturales de la comunidad de los pueblos originarios que lo habitan. Mediante la intervención se pretende:

- mejorar la calidad de vida de la población del sector; - promover programas de acción para la concientización en temas orientados a la seguridad, salud, educación y capacitación laboral;

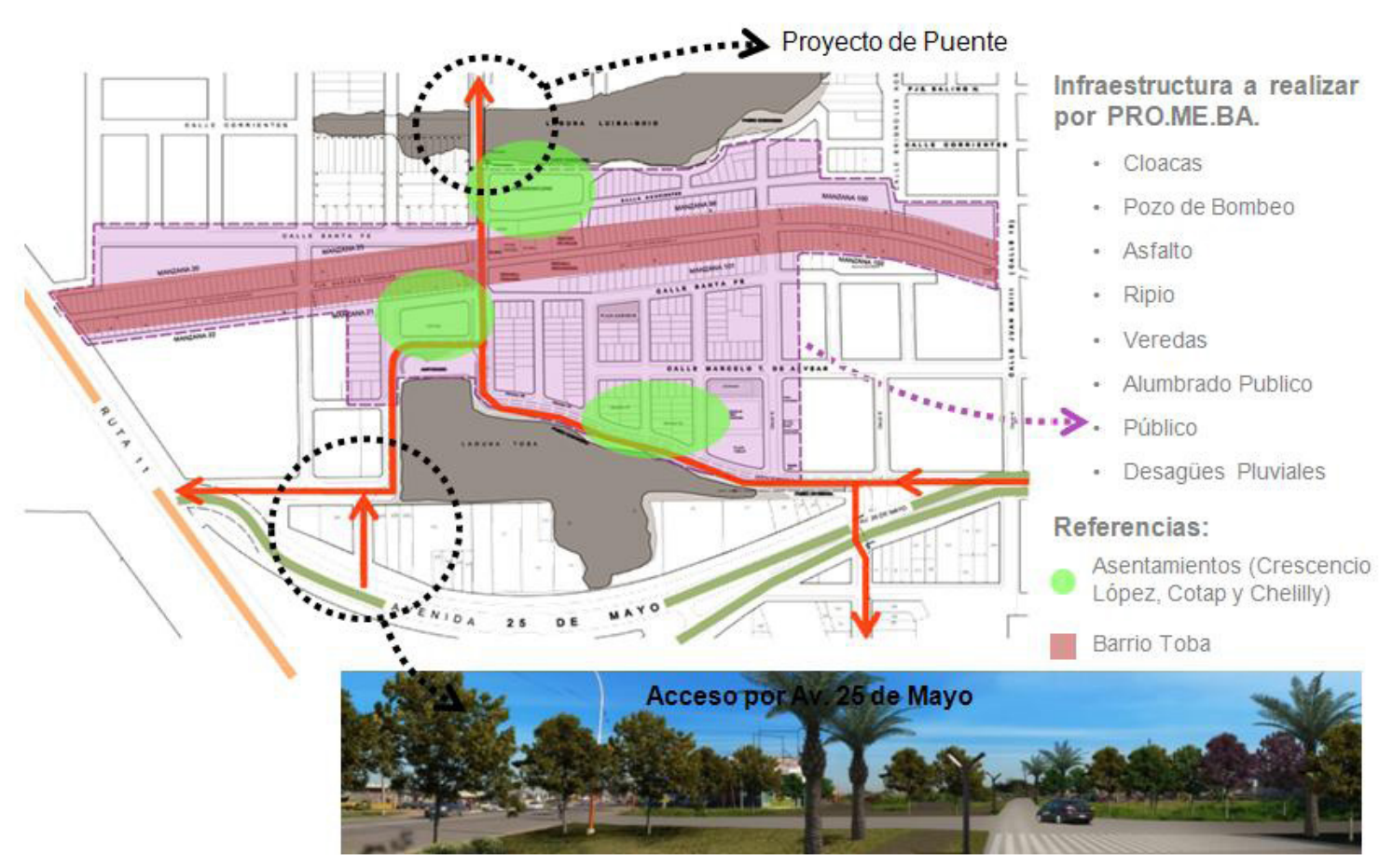

Imagen 5. Área Gran Toba. Zonas de intervención y principales obras. Fuente: equipo técnico IPDUV

mejore las condiciones espaciales y ambientales de todo el entorno, sino que también permita aumentar las oportunidades de inclusión y justicia social para la población que reside en el lugar. Se plantea
- insertar al barrio en la trama urbana para lograr mayor accesibilidad a los servicios e infraestructura; - proveer los equipamientos necesarios (sociales, civiles, religiosos, de salud, de recreación y deportivos) 
"Mediante el proyecto de intervención integral se pretende dar una respuesta sistémica, que no solo mejore las condiciones espaciales y ambientales de todo el entorno, sino que también permita aumentar las oportunidades de inclusión y justicia social "

para el desarrollo de diferentes actividades, considerando la densidad de población del área.

- revalorizar y refuncionalizar las áreas verdes y lagunas para su aprovechamiento a través de actividades de esparcimiento y recreación.

\section{LINEAMIENTOS GENERALES DE ACCIÓN}

En el Proyecto Urbanístico de Intervención Integral del Área Gran Toba se proponen en tres niveles de complejidad:

\section{Escala ciudad / estructural}

El objetivo principal es la regeneración urbanística del sector, la inserción a la trama urbana de la ciudad y una mejor conectividad con ella a través de obras de infraestructura y equipamientos. Para ello se propone una calle de acceso principal desde la Av. 25 de Mayo que bordee la laguna Toba, hasta el centro cívico del barrio, donde se bifurca en dos calles: una es la continuación de la Av. Juan Manuel de Rosas, que por medio de un puente sobre la laguna Luisa-Ghío conecta el sector con los barrios del norte de la cuidad y la trama circulatoria principal; la otra bordea la laguna Toba y se vuelve a conectar con la Av. 25 de Mayo y la ruta nacional N. ${ }^{\circ} 11$.

Mediante estas nuevas calles propuestas se pretende conectar al barrio con las principales vías de acceso de la ciudad y con las zonas aledañas, lo que posibilitaría un circuito o recorrido para el transporte público y mejoraría la accesibilidad de los servicios públicos.

En esta escala se han proyectado otras obras de carácter estructural, que modificarán sustancialmente la calidad de vida de los habitantes del área: cloacas y pozo de bombeo en el sector, alumbrado público, asfalto, ripio, veredas, arbolado, plaza, plazoletas, saneamiento de las lagunas y mejoramiento de desagües pluviales.

Asimismo, considerando que uno de los objetivos principales de la intervención integral del Área Gran

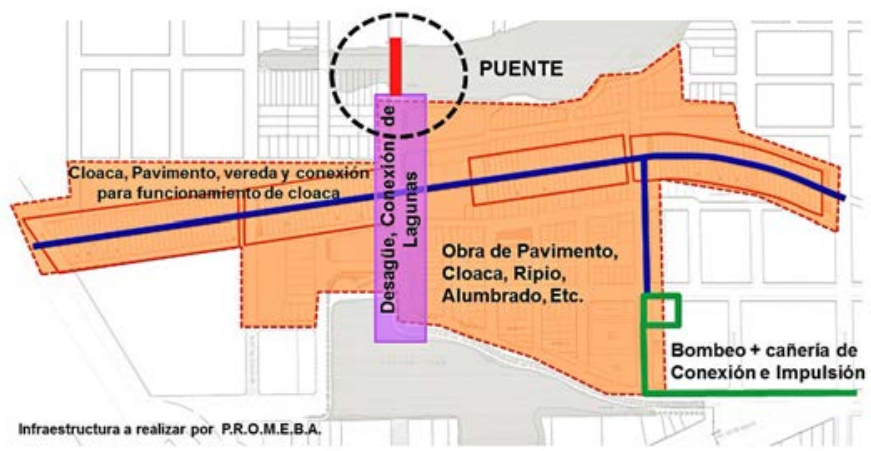

Imagen 6. Área Gran Toba. Obras de Infraestructura con financiamiento del Promeba. Fuente: equipo técnico IPDUV

Toba es la mejora de la calidad de vida de sus habitantes, se ha hecho necesario descomprimir los grupos familiares detectados como plurifamiliares o de "familias extendidas", que por carencia de medios materiales cohabitaban en una misma vivienda. Sin embargo, la cantidad limitada de suelo vacante en el área para la expansión de los barrios ha hecho necesario emprender un proceso de relocalización de familias del Área Gran Toba. Para lograrlo se destinó un sector de la Chacra 24 -al norte de la ciudad, en un sector contiguo al barrio Mapic, cercano al parque Caraguatá- para la ejecución de viviendas nuevas, que darán solución habitacional a parte de las familias extendidas que sufrían graves condiciones de hacinamiento en el Área Gran Toba.

A partir de esta definición, que desdobla la localización original en dos sectores - y origina una segunda intervención integral-, se delinea un complejo trabajo en función de la necesidad de relocalizar familias en un nuevo sector, que fue posible únicamente 


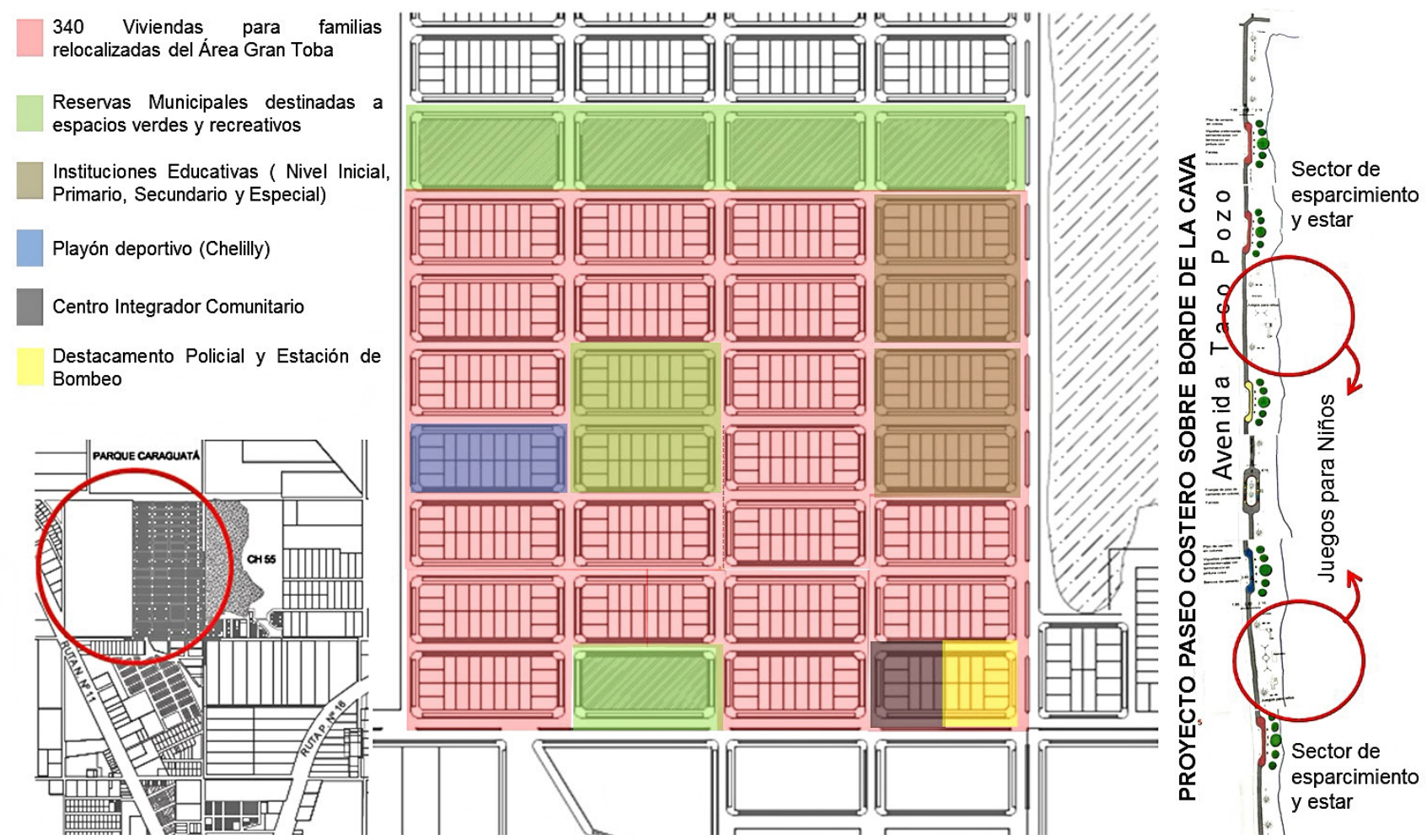

Imagen 7. Área de relocalización definitiva para "familias extendidas" del Gran Toba. Chacra 24. Esquema de distribución de viviendas y equipamiento. Fuente: equipo técnico IPDUV

a partir del permanente consenso con las familias del Área Gran Toba. La elección de esta nueva área de urbanización es estratégica, ya que se ubican allí otros barrios habitados por pobladores originarios y se genera así un nuevo proceso de fortalecimiento cultural de la etnia.

Mediante este proyecto se relocalizarán familias agrupadas en cuatro asentamientos de la misma etnia: asentamiento Crescencio López, asentamiento Cotap, asentamiento Chelliyí, asentamiento Mapic, y familias en condiciones de hacinamiento de la franja del barrio Toba, y se establecen seis grupos de viviendas en función de las necesidades de cada familia. El total al que se arribará al finalizar la ejecución del proyecto asciende a 340 viviendas. Además se llevará a cabo en el área de relocalización una serie de equipamientos que beneficiarán no solo a los nuevos barrios, sino a los existentes en los alrededores: complejo educativo de nivel inicial, primario, secundario y de educación especial, Centro Integrador Comunitario, polideportivo, plazas y áreas recreativas, destacamento de bomberos y policía, entre otros.

\section{Escala barrial}

Corresponde al área de intervención que vincula al barrio original con los barrios aledaños, producto de la ocupación informal. El carácter que se le dará a la calle de acceso pretende bajar la escala del tráfico, pasando de una avenida de alto tránsito de acceso a la ciudad y la ruta nacional $N .^{\circ} 11$, con un tránsito internacional pesado, a una calle barrial donde se prioriza al peatón mediante la construcción de nue- vas veredas, y donde se permite el tránsito vehicular y se prioriza el transporte público. Además, para reforzar la accesibilidad y circulación interna se prevé abrir calles transversales en la actual trama lineal del barrio Toba.

La propuesta pretende recuperar las lagunas con un tratamiento de borde que suma espacios verdes y esparcimiento para todo el barrio, genera paseos peatonales, bicisendas y lugares de estar sobre ambas lagunas. Se plantea mantener la concentración del equipamiento educativo, religioso, social y de salud en las dos manzanas situadas en el centro del barrio, donde se ubican actualmente, mejorar los edificios existentes y proponer nuevos en los lotes disponibles. En la vía de acceso principal se presenta una manzana de equipamiento que sirve a un área más extensa de la ciudad, para el Registro Civil y un Destacamento de Policía, junto a un área deportiva y recreativa.

\section{Escala intralote}

Se trata de la intervención sobre las viviendas. Debido a las malas condiciones en que se encontraban las viviendas en toda el área, y tras un proceso de evaluación de posibilidades de intervención, se definió como necesaria la demolición total de las viviendas existentes y la ejecución de nuevas viviendas. En el caso del barrio original, la aceptación de la necesidad de demolición de las viviendas requirió un intenso trabajo social, técnico y notarial, que posibilitara al mismo tiempo el saneamiento registral de los lotes, que en muchos casos nunca habían sido escriturados a nombre de sus propietarios. Para llevar adelante este 


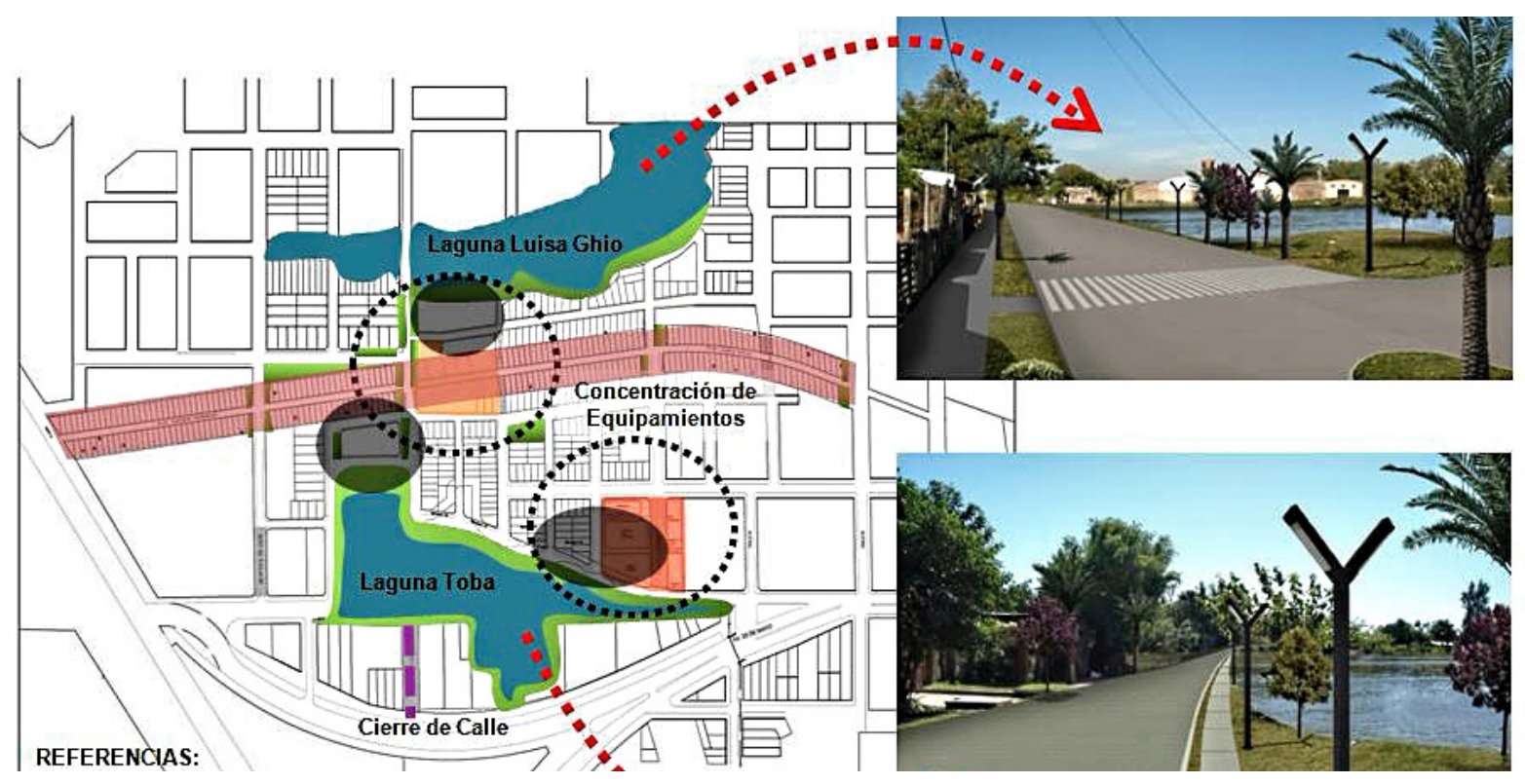

Imagen 8. Área Gran Toba. Escala barrial. Nuevos accesos e intervención de lagunas. Fuente: equipo técnico IPDUV

complejo desafío se proyectaron diferentes tipologías de viviendas, que ofrecían respuestas a las necesidades de cada familia, en función de los relevamientos sociales realizados en el barrio. Los prototipos consensuados con la comunidad son los siguientes:

- Vivienda unifamiliar de dos dormitorios - 52.17 m2 - Vivienda unifamiliar de tres dormitorios - 68.74 m2
- Vivienda unifamiliar de cuatro dormitorios - 81.09 $\mathrm{m} 2$

- Vivienda multifamiliar en un terreno: una vivienda de dos dormitorios en planta baja de $45.80 \mathrm{~m} 2$ + una vivienda tres dormitorios en dúplex de $68.73 \mathrm{~m} 2$

- Vivienda y templo: templo en planta baja 109.53 m2 + una vivienda de dos dormitorios en planta alta $59.90 \mathrm{~m} 2$.

\section{PROYECTO URBANO - PROTOTIPOS}

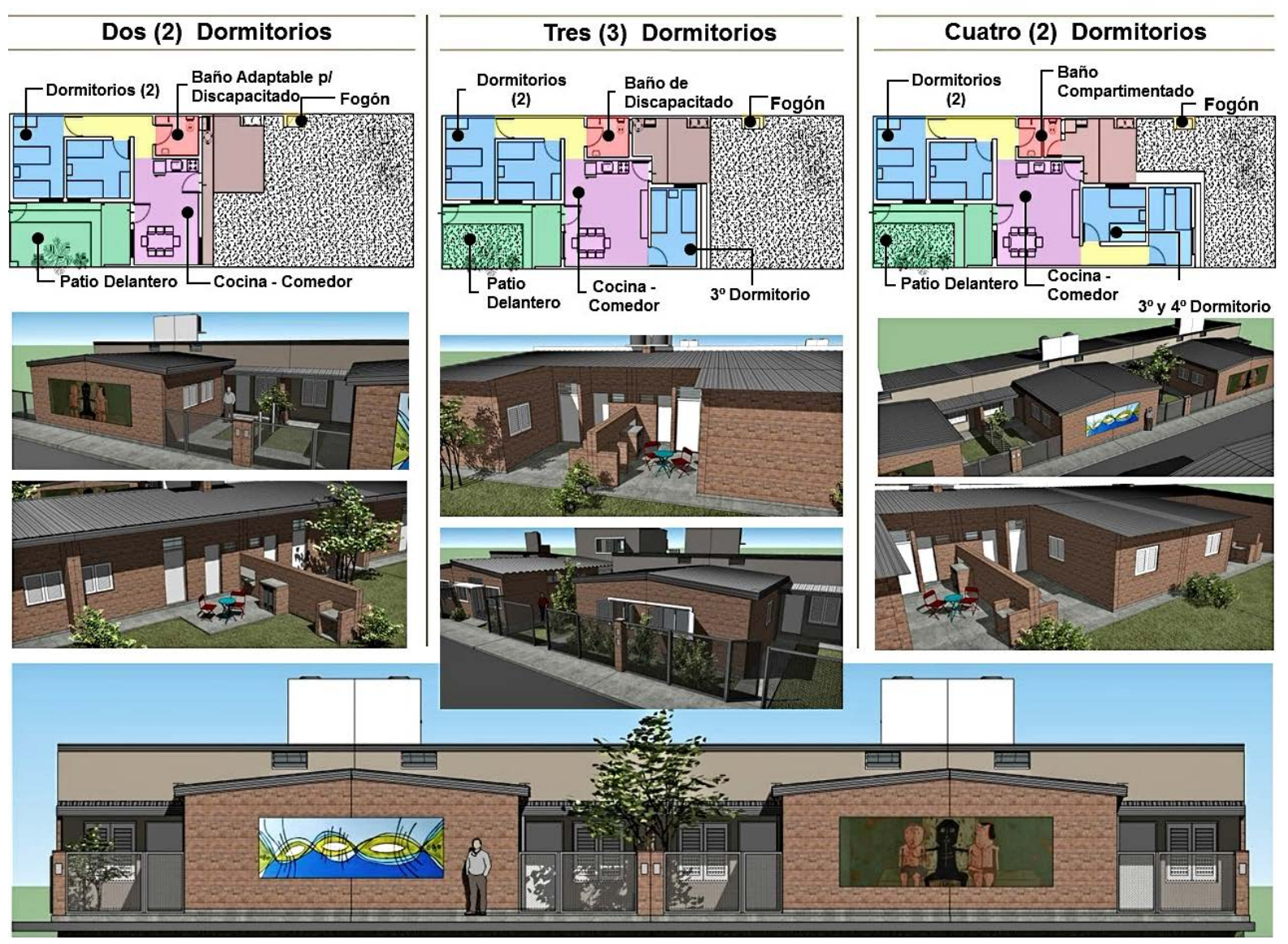

Imagen 9. Área Gran Toba. Escala intralote. Prototipos de vivienda. Fuente: equipo técnico IPDUV 


\section{EL PROCESO DE EJECUCIÓN}

La organización operativa y ejecutiva del proyecto se planteó en diferentes grupos de obras. De esta forma se logró la financiación de las numerosas acciones para la concreción de la propuesta integral a través de distintas fuentes de origen nacional e internacional.

Actualmente se ejecutan cuatro grandes subproyectos que componen el proyecto integral:

1. La readecuación del sector de viviendas familiares pertenecientes al barrio Toba. Actualmente se ejecutan 71 viviendas, correspondientes a dos manzanas de la franja del barrio Toba (cercanas a la ruta 11). Se registra un avance de obra del $30 \%$.

2. El ordenamiento y relocalización de los asentamientos informales Chelliyí, Crescencio López y Cotap ubicados en el entorno inmediato del barrio. Se han concluido 33 viviendas para las familias que habitaban en el asentamiento Crescencio López. Queda pendiente de terminación el perfilado de calles, veredas y alumbrado público del barrio.

Se encuentran en ejecución con un avance del 50 $\%$ quince viviendas para familias del asentamiento Cotap. Asimismo, han sido entregadas 110 viviendas en el área de relocalización definitiva, y se ejecutan otras 42 viviendas con un $85 \%$ de avance.

3. El desarrollo y adecuación de infraestructuras de saneamiento, acceso, veredas y espacios públicos del barrio y el entorno. La ejecución de estas obras registra un $30 \%$ de avance.

4. El saneamiento ambiental de las lagunas Toba y Luisa-Ghío para la recuperación de bordes, espacios públicos de esparcimiento e infraestructura vial de acceso.

El subproyecto 1 reviste uno de los mayores desafíos para el equipo técnico, dado que tiene que ver con la readecuación del sector de viviendas familiares pertenecientes al barrio Toba. En esta etapa, iniciada en enero de 2014, se dispuso de un predio de relo- calización provisoria para albergar a las familias cuyas viviendas fueron demolidas. Mientras las nuevas soluciones habitacionales se encuentran en proceso de construcción, el IPDUV provee a las familias una vivienda de emergencia, por un período aproximado de cuatro a seis meses (estimados para la finalización de cada etapa de obra de ejecución de las viviendas), ubicadas en un predio cercano al barrio. En el predio de relocalización provisoria el Estado Provincial ha dispuesto una serie de acciones interinstitucionales, coordinadas por el IPDUV, para brindar atención integral a las familias en materia de salud, desarrollo social, deportes y ambiente.

El inicio de la demolición y construcción de las viviendas del barrio Toba se dio simultáneamente con el inicio de las obras de construcción de la infraestructura,

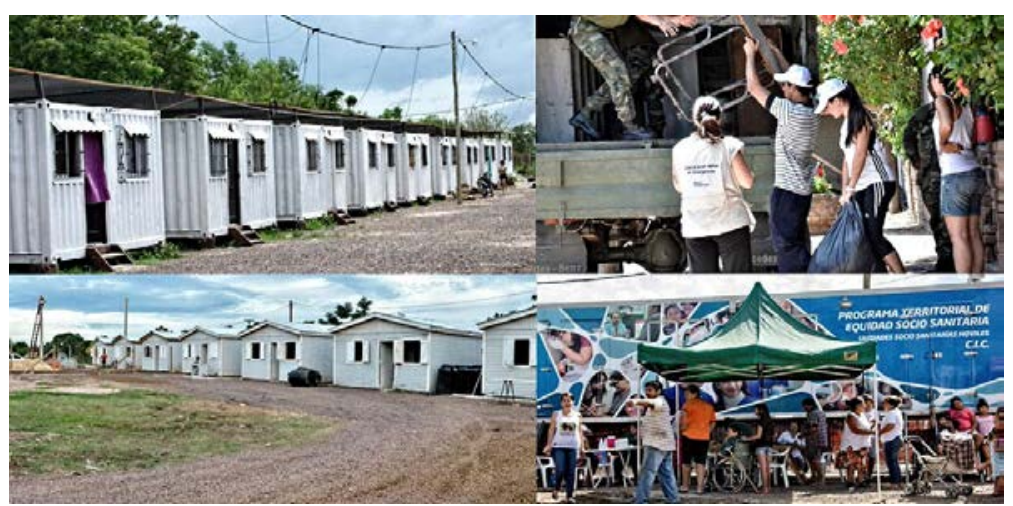

Imagen 10. Relocalización provisoria de familias del barrio Toba. Acciones de atención integral realizadas mediante coordinación interinstitucional. Fuente: equipo técnico IPDUV

siguiendo un proceso lineal y progresivo en cuatro etapas, para lo cual ha sido imprescindible la coordinación con los diferentes organismos intervinientes en la toma de decisiones respecto de cada etapa (demolición, traslado de escombros, construcción de obras de infraestructura, construcción de viviendas, obras de desagües, entre otras).

Los subproyectos 2 y 3 se encuentran en pleno proceso de ejecución, con algunas obras finalizadas. El intenso trabajo social que se ha llevado a cabo en es- 


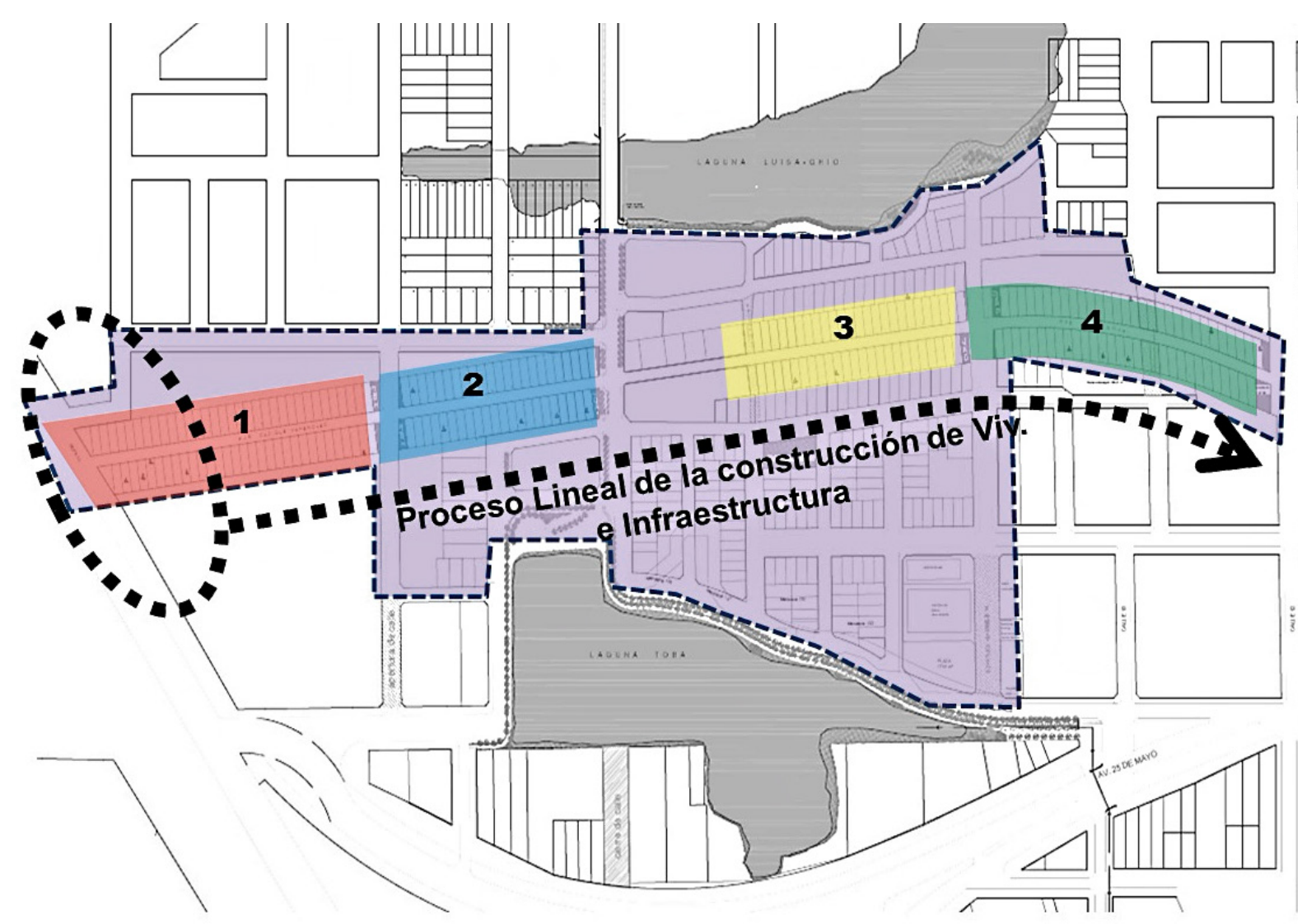

Imagen 11. Proceso lineal de construcción de viviendas e infraestructura del barrio Toba. Fuente: equipo técnico IPDUV

tos barrios permite que las obras se ejecuten con parámetros normales. Para lograrlo fue fundamental el apoyo de los vecinos, quienes han sido partícipes desde el inicio en la toma de decisiones: fueron ellos mismos quienes se encargaron de desmantelar las precarias casillas que habitaban para dar lugar a la construcción de las nuevas viviendas; lograron organizarse y acordar las familias que serían relocalizadas en la Chacra 24 y las familias que permanecerían en el Área Gran Toba con una solución habitacional nueva. Además, las obras de infraestructura de saneamiento que mejorarán las condiciones de vida en Chelliyí, Crescencio López y Cotap también alcanzan a otros barrios cercanos, como el barrio Camalote, en el que habitan muchos de los padres de quienes luego se asentaron en Cresencio López.

Finalmente, el subproyecto 4 plantea un nivel de complejidad superior, dado que con su finalización se logrará el ansiado objetivo de insertar definitivamente el barrio en la ciudad, lo que dotará a los vecinos de accesibilidad a diversos equipamientos del área y de otros barrios y propiciará la inclusión saludable de actividades culturales y de ocio.

La complejidad que representa este subproyecto determinó un trabajo proyectual y operativo especial para la intervención sobre el borde de las lagunas Luisa-Ghío y Toba, que considera apertura de vialidades, la inclusión de infraestructuras de desagües y el mejoramiento de las condiciones sanitarias. Para concretar las obras de este subproyecto se plantea un proceso de intervención por etapas dividiendo las áreas en sectores:

- Sector 1: Laguna Luisa-Ghío

- Sector 2: Laguna Toba Costanera Este

- Sector 3: Laguna Toba Costanera Norte

- Sector 4: Laguna Toba Costanera Oeste

El proyecto especial del Sector 1 Laguna Luisa-Ghío comprende el saneamiento e intervención paisajística del primer tramo de la laguna, que se inicia desde de la Av. Juan Manuel de Rosas y se extiende por cien metros.

El proyecto especial de intervención sobre el borde de la laguna Toba se divide en tres sectores, y se propone iniciar las obras por el Sector 2: Laguna Toba Costanera Este, ya que resulta imprescindible vincular el barrio mediante la apertura de calles y ganar superficie útil para el planteo actividades sociales. La intervención en este primer tramo tiene como objetivo el mejoramiento de la accesibilidad y conectividad al área urbana integrada por los barrios Toba, Chelliyí, Crescencio López y Cotap, mediante la apertura de una calle paralela a la laguna Toba sobre el borde este (continuación de la Av. 25 de Mayo) que se vincula directamente con la continuación de la Av. Juan Manuel de Rosas. Esto permitirá la clara y segura circulación vehicular y peatonal, así como también la inserción de recorridos de transporte público de pasajeros, inexistentes en la actualidad. El carácter que se le da a la avenida de acceso al barrio tiene como intención re- 
ducir la escala del tráfico vehicular, de modo tal que se priorice la circulación de transporte público, motocicletas, bicicletas y peatones.

Por otro lado, se proyecta el saneamiento ambiental de la laguna Toba y la recuperación de espacio útil para el desarrollo de actividades de recreación y esparcimiento. El tratamiento del borde de la laguna dará lugar a un paseo costero que propicie el recorrido peatonal, las actividades de estar y de comercio itinerante, como ferias y exposiciones de artesanías típicas de las comunidades qom.

Se ha de tener en cuenta que para el desarrollo de dicho proyecto será necesario el planteo y definición de sectores de relleno de borde de la laguna que respeten adecuadamente la línea de ribera establecida por la Administración Provincial del Agua, considerando un adecuado plan de compensación. Para ello, como parte del plan integral, se prevé la reutilización de los desechos residuales de demolición de las viviendas del barrio Toba debidamente clasificados. Asimismo resultará necesario extender la canalización proveniente desde la laguna Seitor para que el sistema de vinculación entre lagunas siga funcionando.

Los sectores 3 y 4, que comprenden intervenciones en el área costera norte y oeste de la laguna se concretarán en una etapa posterior con definición ajustada del proyecto. Paralelamente, mediante el Programa de Mejoramiento de Barrios (Promeba) se desarrollará el proyecto de sistema de desagües pluviales troncales y canalización que involucra el sistema de lagunas en toda el área: aportes a la laguna Toba desde la laguna Seitor, conexión con la laguna Luisa-Ghío y vinculación final con la laguna Ávalos, donde se ubica la estación de bombeo pluvial "Laguna Ávalos". 